\title{
Effect of Exclusion of Solar UV radiation on Plants
}

\author{
Sunita Kataria ${ }^{凶}$, Sanjay S. Baroniya, Lokesh Baghel and Mansi Kanungo
}

\begin{abstract}
UV exclusion studies can provide the realistic assessments of sensitivity of plant to current level of UV radiation. Perusal of relevant literature reveals that UV exclusion causes enormous increase in the growth of aerial parts along with below ground parts of the plants. Exclusion of UV-B (280-315 $\mathrm{nm})$ and UV-A+B (280-400 nm) enhanced the photosynthetic pigments, net photosynthetic rate and stomatal conductance along with remarkable increase in the activity of Carbonic anhydrase, Rubisco and PEPCase. UV excluded plants have higher PS II efficiency, reducing power, $\mathrm{CO}_{2}$ fixation and decreased UV-B absorbing compounds, channeling the additional fixation of carbon to improvement of yield. UV exclusion studies indicate that dicot plants are more sensitive than the monocot plants to current level of UV-B.
\end{abstract}

Keywords: carbon metabolism; PS II, photosynthesis, UV exclusion, rubisco, UV-B

\section{Introduction}

UV radiation (200-400 $\mathrm{nm}$ ) is harmful to all organisms mainly due to DNA damage and production of reactive oxygen species (Mazza et al., 1999, p. 61). The environmental implication of increasing solar UV-B radiation on agricultural production has heightened

Received: 15 May 2014

Accepted revised version: 14 November 2014

Published online: 03 December 2014

(C) Kataria et al (2014)

Publisher: Horizon e-Publishing Group

CITATION

Kataria, S., Baroniya, S. S., Baghel, L., \& Kanungo, M. (2014).

Effect of Exclusion of Solar UV radiation on Plants. Plant Science Today, 1(4), 224-232. doi: 10.14719/pst.2014.1.4.61

AUTHOR'S AFFILIATION

School of Life Sciences, Devi Ahilya University, Khandwa Road, Indore 452 001, India.

CORRESPONDENCE

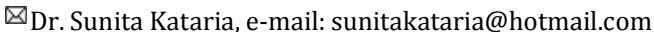

concern due to decrease in stratospheric ozone as a result of the chlorofluorocarbons in the atmosphere (McKenzie et al., 2011). In global agriculture, now effect of UV-B radiation on plants is of major concern to plant biologists due to the threat to productivity. An elevation in the flux of UV-B (280-315 $\mathrm{nm}$ ) is an important atmospheric stress and is detrimental to plant growth and photosynthesis (Reddy et al., 2013). At the metabolism level, UV-B severely inhibits photosynthesis (Reddy, Kakani, Zhao, Koti, \& Gao, 2004, p.416; Kataria, Guruprasad, Ahuja, \& Singh, 2013) and hampers nodulation and nitrogen fixation (Rajendiran, \& Ramanujam, 2006, p.50), changes in the carbon partitioning from growth pools to secondary metabolic pathways (Bassman, 2004) and thus changes in crop morphology, crop reproductive organ abortion and yield reduction (Mohammed, \& Tarpley, 2010) in sensitive plants. On the other hand, UV-A (315-400 nm) is considered less harmful than UV-B radiation. The enhanced levels of pigments such as chlorophyll, carotenoids, and UV-absorbing compounds, including antioxidants, and has been reported to stimulate growth in general by supplementation of UV-A with photosynthetically active radiation (PAR, 400-700nm) (Shiozaki, Hattor, Gojo, Tezuka, 1999; Helspar et al., 2003, p.117). UV-A irradiation is moreover reported to alleviate the damaging effect of UV-B (Flint \& Caldwell, 1996).

Most of the previous research dealing with the effects of UV-B and UV-A radiation on plant metabolism has been conducted in greenhouse, growth chamber or laboratory conditions. These types of indoor experiments are important for understanding the physiology of the UV response. The two most widely used approaches in outdoor studies are the attenuation approach (UV exclusion studies with filters) and the enhancement/supplementation approach (high UV-B provided). While the field studies with supplemental/enhanced UV-B provide information on mechanisms and processes of UV-B action. The enhancement studies supplement solar UV-B with fluorescent lamps to mimic future UV-B enhancements due to ozone depletion but the UV exclusion studies can 
provide the realistic assessments of sensitivity of plant species or varieties to current level of UV-A and UV-B radiation (Rousseaux, Flint, Searles, \& Caldwell, 2004). The reduction of UV-B from ambient level may lead to increase in biomass production in various land plants (Mazza et al., 1999, p. 61; Xiong, \& Day, 2001; Kataria et al., 2013, p.140). Sensitivity to ambient UV-B radiation varies considerably within and between plants species, a high intraspecific variation in plant response to ambient UV-B radiation has been observed after the exclusion of solar UV components as demonstrated in many crops (Kataria, \& Guruprasad, 2012 a, b; Kataria et al., 2013, p.140; Kataria, \& Guruprasad, 2014).

The intensity of UV-B radiation reaching the biosphere is dependent on solar zenith angle, thickness of the ozone layer clouds and aerosols. In tropics due to small solar zenith angle and thin stratospheric ozone layer, terrestrial plants encounter much higher levels of UV-B radiation than at higher latitudes. Thus to evaluate the possible consequences of increased UV-B radiation for tropical plants, it is important to elucidate the effects of present ambient UV level. The effect of ambient UV-B and UV-A can be best assessed by the exclusion of UV components, with specific type of filters that exclude UV-B $(<315 \mathrm{~nm})$, $\mathrm{UV}-\mathrm{A}+\mathrm{B}(<400 \mathrm{~nm})$, transmits all the UV $(280-400 \mathrm{~nm})$. This review provides an overview of existing literature on the effects of the exclusion of solar ultraviolet radiation on growth and subsequently on yield of crop plants.

\section{Effects of UV exclusion on plants \\ 2.1 Plant Growth and Biomass Accumulation}

Reduction in growth is one of the most common responses to enhanced and ambient UV-B. Exclusion of UV-B alone and UV-A/B both from solar radiation caused a significant increase in the growth (plant height, leaf area, specific leaf weight, leaf weight ratio) and biomass production in many plant species like barley, cotton, mung bean and pea, pumpkin, soybean, Cyamopsis, wheat, sorghum and amaranthus (Pal, Sharma, Abrol, \& Sengupta, 1997, Pal, Zaidi, Voleti, \& Raj, 2006; Mazza et al., 1999, p. 61; Amudha, Jayakumar, \& Kulandaivelu, 2005; Guruprasad et al., 2007; Kataria, \& Guruprasad, 2014). Exclusion of ambient UV-B produced more branches in dicots or tillers in monocots with a larger leaf area in barley, cotton and sorghum (Mazza et al., 1999, p. 61; Coleman, \& Day, 2004). Root biomass, number of nodules and nodule fresh weight were also enhanced after exclusion of solar UV (Sharma, \& Guruprasad, 2012). Rinnan et al., (2005, p.11) showed that below ground biomass of Vaccinium uliginosum is reduced under ambient UV-B when compared to UV-B exclusion. UV exclusion studies reveals that dicots like mung bean, pea, cotton, soybean and amaranthus are more sensitive to solar UV-B than monocots like maize, sorghum and wheat (Pal et al., 1997, p. 29, Pal et al., 2006, p.19; Kataria et al.,
2013, p.140) while it does not differ between $C_{3}$ and $C_{4}$ plants. Thus the UV components present in the solar spectrum seemed to inhibit the growth and biomass accumulation whereas exclusion of solar UV-B and UV-A/B from the solar radiation causes significant enhancement in morphological changes in the crop plants.

\subsection{Non Photosynthetic Pigments}

Generally, accumulation of UV-B absorbing substances, mainly flavonoids, in leaf epidermis was suggested to be a protective measure against UV-B effects. The two main groups of phenolics that provide protection from UV radiation are the flavonoids and hydroxycinnamic acids, these compounds have absorption bands in the ranges 240-545nm and 227-332 nm, respectively (Cerovic et al., 2002). Both groups of phenolics protecting the inner cells from the harmful radiation (Bassman, 2004) and act as sunscreens in the leaf epidermis while transmitting photosynthetically active radiation (PAR) to the mesophyll cells. Flavonols strongly absorb UV and have high antioxidant activity (Jenkins, 2008, p.240), and thus they are very important for UV-B tolerance in plants (Hofmann et al., 2000,p.527; Balouchi, Sanavy, Emam, \& Dolatabadian, 2009, p. 443).

Epidermal flavonoids in vivo decreased, when UV-B was excluded and the concentrations of six flavonoids (myricetin-3-galactoside, quercetin-3-galactoside, quercetin-3-glucuronide, quercetin-3-arabinopyranoside, quercetin-3-rhamnoside and kaempferol-3-rhamnoside) determined by high-performance liquid chromatography-mass spectrometry were also decreased with the exclusion of UV-B (Morales et al., 2010). Thus previous studies demonstrated that the increases in flavonoids and other phenolic compounds in plants could protect mesophyll cell from UV-B radiation damage and exclusion of solar UV decreases these compounds due to elimination of defense against UV-B damage. Since UV-B induces the synthesis of flavonoids (Jenkins, 2009), it is not unexpected that concentrations of certain flavonoids are lower in environments with reduced UV-B. Some other field experiments have also confirm that leaf flavonoid contents can decrease with UV-B exclusion, for example in Pinus sylvestris (Turunen et al., 1999) and Nothofagus antarctica (Rousseaux et al., 2004, p.224) and Amaranthus tricolor (Kataria, \& Guruprasad, 2014).

\subsection{Photosynthetic Pigments}

The pronounced decrease in the amount of photosynthetic pigments by ambient and enhanced UV-B may possibly affect photosynthesis and reduce both biomass accumulation and economic yield (Yao et al., 2006). The chlorophyll components, thylakoids and grana were sensitive to the incoming solar radiation (He, Huang, Whitcross, 1994). An increase in UV-B radiation resulted in rupture of the thylakoids and grana due to the 
disintegration of the membranes (He et al., 1994, p.771). The significant increase of total chlorophyll occurred under reduced UV-B and $\mathrm{UV}-\mathrm{A}+\mathrm{B}$ radiation, and this implied that the UV radiation has a negative impact on the parameters related to photosynthesis. The exclusion of solar UV-B and UV-A+B caused enhancement in photosynthetic pigments like- Chlorophyll $a$ (Chl $a$ ), Chl $b$, total $\mathrm{Chl}$ and carotenoid content per unit fresh weight. The increase in total $\mathrm{Chl}$ level by the exclusion of solar UV was due to the enhanced synthesis of Chl $a$ and $\mathrm{Chl} b$. Though the extent of promotion was greater in $\mathrm{Chl} b$ rather than $\mathrm{Chl} a$, which cause the decrease in the ratio of $\mathrm{Chl} a / b$ after exclusion UV-B and UV-A+B (Amudha et al., 2005, p.284; Kataria et al., 2013, p.140). Chl $a / b$ could reflect the relative ratio of stacked regions to unstacked regions, which were inversely proportional to the stacking degree of thylakoids (Ibanez et al., 2008).

Carotenoids are also significantly increased by exclusion of solar UV (Amudha et al., 2005 p. 284; Kataria et al., 2013, p.140). They play an important role against UV-B damage in higher plants. Carotenoids, the scavengers of singlet oxygen species formed during intense light, are involved in the light harvesting and protection of chlorophylls from photoxidative destruction (Middleton \& Teramura, 1993). The reduction in carotenoids in presence of solar UV-B and UV-A could have serious consequences for UV-B radiation effects on chlorophyll pigments, its role in the photoprotection of the photosynthetic system by dissipating excess excitation energy through the xanthophylls cycle (Demmig-Adams, \& Adams, 1992, p.599). On the other hand, on removal of the stress, the inhibition is overcome or degradation processes might have been 'stopped, resulting in an accumulation of these pigments.

\subsection{Chlorophyll Fluorescence}

Chlorophyll fluorescence analysis is a powerful technique to conveniently assess the condition of PSII and vitality in intact plants. He et al. (1993) observed that decrease in the ratios of variable to maximum chlorophyll fluorescence yield and in the quantum yield of photosynthetic oxygen evolution by supplemental UV-B in pea and rice leaves. In contrast to UV-B, UV-A is not usually regarded as a potentially damaging stress factor, although Turcsanyi and Vass (2000) reported the UV-A induced impairment of photosystem II and concluded that UV-A radiation is highly damaging for PSII, and affected the electron transport at both the water oxidizing complex, and the binding site of the $\mathrm{Q}_{\mathrm{B}}$ quinone electron acceptor in a similar way to that caused by UV-B radiation. Hakala-Yatkin, Mäntysaari, Mattila, \& Tyystjärvi (2010) studied the contribution of the UV part of sunlight in photoinhibition of PSII in leaves and also suggested that especially the UV-A part, are potentially highly important in photoinhibition of PSII by the means a UV-permeable or UV-blocking filters.

On the other hand reduction of the UV-B and UV-B+A both caused a rise in many of the Chlorophyll fluorescence parameters in several crops. The UV-exclusion experiments showed that a reduction of the ambient UV-B level resulted in decreased content of UV-B absorbing compounds and lower stress level indicated by increased maximal quantum yield $\left(\mathrm{F}_{\mathrm{V}} / \mathrm{F}_{\mathrm{M}}\right)$ and Performance Indexes (PI) (Bredahl, Ro-Poulsen, Mikkelsen, 2004; Albert et al., 2005, 2008, 2010; Kataria et al., 2013, p.140). Bredahl et al. (2004, p.363) reported higher maximal photochemical efficiency (measured as the chlorophyll fluorescence parameter Fv/Fm) under UV-B reduction. Quantum efficiencies, specific and phenomenological fluxes were all enhanced by UV exclusion indicating a negative impact of ambient UV on all of these parameters in the plant species (Albert, Mikkelsen, \& Ro-Poulsen, 2005, Albert, Mikkelsen, \& Ro-Poulsen, 2008, Albert et al., 2010, p.1542; Kataria et al., 2013, p.140). The increases in the efficiency that an absorbed photon will be trapped by the PSII reaction centre with the resultant reduction of $Q_{A}$ to $Q_{A}-$ (ET0/ABS $=\mathrm{FV} / \mathrm{FM}$ ) and the efficiency that an electron residing on $\mathrm{Q}_{\mathrm{A}^{-}}$will enter the intersystem electron transport chain (ET0/TR0) were observed in reduced UV-B. Moreover, estimated per cross-section of leaf sample, the number of active PSII reaction centres (RC/CSM) and electron transport rate (ETM/CSM) and all performance indexes (PIABS, PICSo and PICSm) were increased in reduced UV-B (Albert et al., 2005, p.208, Albert et al., 2008, p.199; Kataria et al., 2013, p.140).

Among the constellation of JIP (a test applied to analyze fast fluorescence kinetics 0-J-I-P) expressions, one of the most sensitive parameters are the performance index $\left(\mathrm{PI}_{\mathrm{ABS}}\right)$. Moreover, $\mathrm{PI}_{\mathrm{ABS}}$ allows broader analysis of photosynthetic performance such as the relationship between photon absorption efficiency and capture of excited energy in PS II, as well as analysis of density of active RC and the probability that excited energy moves an electron further than $\mathrm{Q}_{\mathrm{A}^{-}}$(Goncavles, \& Junior, 2005), all of these parameters were significantly increased after exclusion of UV-B and UV-A+B (Kataria et al., 2013, p.140). Their enhancement clearly indicates an improved overall processing of light energy per leaf sample CS in UV excluded plants (Albert et al., 2005, p.208, Albert et al., 2008, p.199; Albert et al., 2010, p.1542; Kataria et al., 2013, p.140). The leaves of UV excluded plants species had higher reducing power with higher efficiency of electron transport and more active reaction centers, which may lead to the increase in carbon uptake in these plants (Albert et al., 2005, p.208, Albert et al., 2008, p.199; Albert et al., 2010, p.1542; Shine, \& Guruprasad, 2012; Kataria et al., 2013, p.140; Kataria, \& Guruprasad, 2014). 
These findings clearly indicate that ambient UV-B and UV-A impacts on photosynthetic performance of plants by reducing maximum photosynthetic yield of PSII (Xiong, \& Day, 2001; Albert et al., 2005, p.208; Albert et al., 2010, p.1542; Albert et al., 2011, p.439; Kataria et al., 2013, p.140; Kataria, \& Guruprasad, 2014). Thus solar UV components inhibit photosynthetic efficiency of plants. This inhibition can be related to higher production of active oxygen species, which can cause multi-targeted deleterious effect on PS II components (Shine \& Guruprasad, 2012).

\subsection{Photosynthesis (Pn)}

The process of photosynthesis is considered to be sensitive to UV-B radiation. The reductions in rate of photosynthesis have been attributed to changes in photophosphorylation, electron transport and carbon assimilatory processes (Teramura, 1983). Current ambient levels of UV radiation have been shown to modify leaf morphology and gas exchange in Populus, and increased net photosynthesis was observed under sub-ambient (-UV-B) radiation (Schumaker, Bassman, Robberecht, \& Radamaker, 1997). Similarly, Krause et al. (2003) have reported a reduction in net $\mathrm{CO}_{2}$ uptake and photosystem I efficiency in tree seedlings when exposed to solar UV-B radiation. Reduction in biomass has been linked with reduced rate of photosynthesis in many crop species after supplemental UV-B and ambient UV-B (Kataria et al., 2013, p.140; Pal et al., 1997, p.29; Ambasht \& Agrawal, 1998). Moussa \& Khodary (2008) found a higher photosynthetic capacity in UV-B-free grown common bean plants (up to $33 \%)$ against only a marginal increase (12\%) in barley plants grown under similar conditions. A similar observation of enhancement in the net rate of photosynthesis and concomitant increase in stomatal conductance after exclusion of UV-B has been made in Populus (Schumaker et al., 1997, p.617), maize and mung bean (Pal et al., 1997, p.29), wheat and pea (Pal et al., 2006, p.19), sorghum (Kataria, \& Guruprasad, 2012b), Amaranthus tricolor (Kataria, \& Guruprasad, 2014) and Vaccinium uliginosum (Albert et al., 2008, p.199). The primary effect of ambient UV is thus on the photosynthetic performance that reduces rate of photosynthesis and fixation of $\mathrm{CO}_{2}$. Variation in photosynthesis is also dependent on the ability of a leaf to draw down $\mathrm{CO}_{2}$ within the leaf. Lower stomatal conductance suggests a direct impact of UV-B on stomatal closure (Day, \& Vogelmann, 1995) and stomatal limitation accounting for the decline in photosynthesis. UV-B radiation has the potential to affect the stomatal density in pea (Nogués, Allen, Morison, \& Baker, 1998).

\subsection{Enzymes related to carbon metabolism}

Enhanced and ambient UV-B significantly inhibits net photosynthetic rate as the consequences of decrease in the light saturated rate of $\mathrm{CO}_{2}$ assimilation, accompanied by decreases in carboxylation velocity and Rubisco content and activity (Allen, Mckee, Farage \& Baker, 1997). Limited $\mathrm{CO}_{2}$ assimilation due to UV-B leads to excessive production of ROS which, in turn, cause oxidative damage in plants (Strid, Chow \& Anderson, 1994). Rao, Palijyath, \& Ormrod, (1996) suggested that UV-B exposure generates activated oxygen species by increasing NADPH-oxidase activity. The productions of hydroxyl radicals, singlet oxygen, superoxide radicals and hydrogen peroxide have been detected in response to UV-B exposure. It has been suggested that exposure to UV-B results in generation of ROS within the chloroplast, as thylakoid membranes are very rapidly perturbed on exposure to UV-B radiation (Chow, Strid, \& Anderson, 1992).

Hence the decrease in Pn by ambient UV might be associated with changes in the activities of enzymes involved in carbon assimilation along with damage to PSII. Ribulose-1,5 biphosphate carboxylase/oxygenase (Rubisco) is the primary catalyst for the assimilation of atmospheric $\mathrm{CO}_{2}$ in to the biosphere. It is a key enzyme in $\mathrm{C}_{3}$ cycle of photosynthetic fixation of $\mathrm{CO}_{2}$ and a remarkably abundant protein (upto 65\% of total soluble leaf proteins) (Furbank, \& Taylor, 1995). In $\mathrm{C}_{4}$ photosynthetic carbon metabolism, the initial carboxylation reaction is catalyzed by phosphoenolpyruvate carboxylase (PEPC). PEPC utilizes bicarbonate rather than $\mathrm{CO}_{2}$ as the inorganic substrate (O'Leary, 1982). To sustain this process, atmospheric $\mathrm{CO}_{2}$ entering the mesophyll cells must be rapidly converted to $\mathrm{HCO}_{3}$-and this reaction is the critical first step of $\mathrm{C}_{4}$ photosynthesis (Hatch \& Burnell, 1990). Carbonic anhydrase (CA) plays an important role in the acceleration of carbon assimilation, by catalyzing the reversible interconversion of $\mathrm{CO}_{2}$ and $\mathrm{HCO}_{3}{ }^{-}$. In leaves $\mathrm{CA}$ represents $1-20 \%$ of total soluble protein and abundant next only to Rubisco in chloroplast. In $\mathrm{C}_{3}$ plants, CA activities largely restricted in stroma of mesophyll chloroplasts, where it is believed to facilitate the diffusion of $\mathrm{CO}_{2}$ across the chloroplast envelope. In $\mathrm{C}_{4}$ plants, however most of the CA activity is found in mesophyll cells, where PEP carboxylase is also located (Hatch \& Burnell, 1990). Co-existence and feeding of Rubisco in $\mathrm{C}_{3}$ plants and PEPC in $\mathrm{C}_{4}$ plants with carbon source by $\mathrm{CA}$ assumes the special significance of $\mathrm{CA}$ as an efficient biochemical marker for carbon sequestration and environmental amelioration in the current global warming scenario linked with elevated $\mathrm{CO}_{2}$ concentration.

The recent reports in lower and higher plants, suggests that ambient level of UV-B and UV-A radiations affect the activity of carbonic anhydrase, Rubisco and PEPCase. Exclusion of UV-B and UV-A+B from solar spectrum resulted in an elevated overall activity of carbonic anhydrase, RuBisco and PEPcase and increase in its concentration (Bischof, Hanelt, \& Wiencke, 2000; 
Bischof, Krabs, Wiencke, \& Hanelt, 2002; Kataria et al., 2013, p. 140; Kataria, \& Guruprasad, 2014). The increase in CA activity by exclusion of UV radiations may enhance the fixation of $\mathrm{CO}_{2}$ via PEP carboxylase as well as via Rubisco. UV-B exposure has been shown to lead to a reduction in the expression and level of key photosynthetic proteins including Rubisco (Allen, Nougúes, \& Baker, 1998). Bischof et al. (2002, p.502) observed an increase in the concentration and the activity of Rubisco in Ulva lactuca after exclusion of solar UV. The enhancement in the activity of Rubisco by the fixation ${ }^{14} \mathrm{CO}_{2}$ was found in $\mathrm{C}_{3}$ and $\mathrm{C}_{4}$ monocot/dicot crop species by the exclusion of solar UV components (Kataria et al., 2013, p.140). The enhanced activity of CA, Rubisco and PEP carboxylase in the absence of solar UV radiation could be due to degradation of protein subunits upon exposure to UV-B as shown for higher plants and macroalgae (Bischof et al., 2000, p.555; Bischof et al., 2002, p.502; Xu, Natarajan, \& Sullivan, 2008). Damage to enzyme proteins such as Rubisco could also results from the active oxygen species formed under UV-B radiation (Shine, \& Guruprasad, 2012). With regard to the degradation of Rubisco, Ishida et al. (1998, 1999) demonstrated that under illumination the large subunit (LSU) of Rubisco could be directly fragmented into two polypeptides by reactive oxygen species in chloroplast. In addition, Desimone et al. (1996, 1998) reported that light stress induced reactive oxygen-mediated denaturation of Rubisco followed by proteolytic degradation of LSU in chloroplasts. Elevated UV-B induced injury might be associated with active oxygen species in rice (Dai et al., 1997, p.301); this has also been found in other species (Mackermess, Surplus, Jordan, \& Thomas, 1998). However, it should be noted that the fast rate of degradation of Rubisco occurred after the leaf had developed to maturity, around that time active growth of the leaf drew near the end and senescence began. Thus, it can be speculated that the formation of proteases may be increased at this point, resulting in enhanced Rubisco degradation (Callis, 1995). However, the future studies needed for the molecular mechanisms behind the Rubisco degradation

\subsection{Crop yield}

In the natural environment plants are usually subjected to combined stresses and the stress factors cause several changes in plant metabolism and morphology. The main concern for producers and agricultural scientists is whether or not enhanced UV-B radiation due to stratospheric $\mathrm{O}_{3}$ depletion reduces economic yields and product quality of field crops. The UV components present in the solar spectrum seemed to inhibit the photomorphogenetic pattern. Exclusion of ambient UV has a potential for producing higher biomass/yield which gets limited under ambient UV. Removal of UV from solar radiation caused a significant increase in yield attributes like number of pods and seeds, weight of seeds in cymopsis (Amudha et al., 2005, p.284) and soybean varieties (Baroniya, Kataria, Pandey, \& Guruprasad, 2011). Germ et al. (2005) found that exclusion of UV-B from the solar radiation led to more than double the yield of pumpkin fruits. The reason for yield reduction may be due to alterations in plant vegetative and reproductive growth, e.g., plant stunting, flower suppression and/or delay of flowering and lower pod set (Saile-Mark, \& Tevini, 1997; Amudha et al., 2005, p.284). High level of UV-B radiation delays flowering and thereby reducing the yield. In the case of Cyamopsis, a delay in the onset of flowering was observed in the ambient light grown plants. The cause for the delay is maybe due to the impact of solar UV radiation on the biosynthesis of gibberellins as explained by Saile-Mark (1993) in Hyoscyamas niger. Exclusion of UV-A along with UV-B enhanced the yield parameters in terms of weight of total bolls and fibers in cotton; number of leaves and foliage yield (fresh weight of leaves) in amaranthus; number of ears/panicles, grains and grain yield per plant in wheat and sorghum, the extent of promotion in yield parameters was more by exclusion of UV-B alone than the exclusion of UV-A+UV-B (Kataria et al., 2013, p.140).

Reduction in photosynthesis by ambient UV (280-400 $\mathrm{nm}$ ) radiations is a basis of reduced dry matter production and lower yield. Enhanced production of UAS by ambient UV-B, suggests that the reduced photosynthesis may be due to, diversion of primary metabolites towards the protective sunscreens and in results in reduced secondary metabolism. While in the absence of ambient UV-B; the reduction in the synthesis of these secondary products (UAS) can save the carbon that can be channelized to primary metabolism. Since secondary and primary metabolic pathways compete for the common pool of carbon, reduction in secondary metabolism by the exclusion of solar UV-B and UV-A+UV-B can channelize the carbon to improved biomass accumulation and increased rate of Pn which ultimately results in improvement of crop yield (Fig. 1). The exclusion of UV components from the solar radiation brings about a larger increase in the vegetative growth, pigments as well as in crop yield in certain crops, however, these changes are species specific.

\section{Conclusions}

Exclusion studies will have significance under tropical environment where the plants receive higher amount of ambient UV-B. Exclusion studies would help in the assessment of the adaptability of a variety to ambient UV-B received. Exclusion of UV components from solar radiation under field condition stimulates plant growth and enhanced biomass. This increased growth and biomass appear to be due to the better harvesting of light and lower level of free radicals in plants grown under UV-B and UV-A+B exclusion filters. The economics feasibility of using this technique is currently being marked out. Instead of 


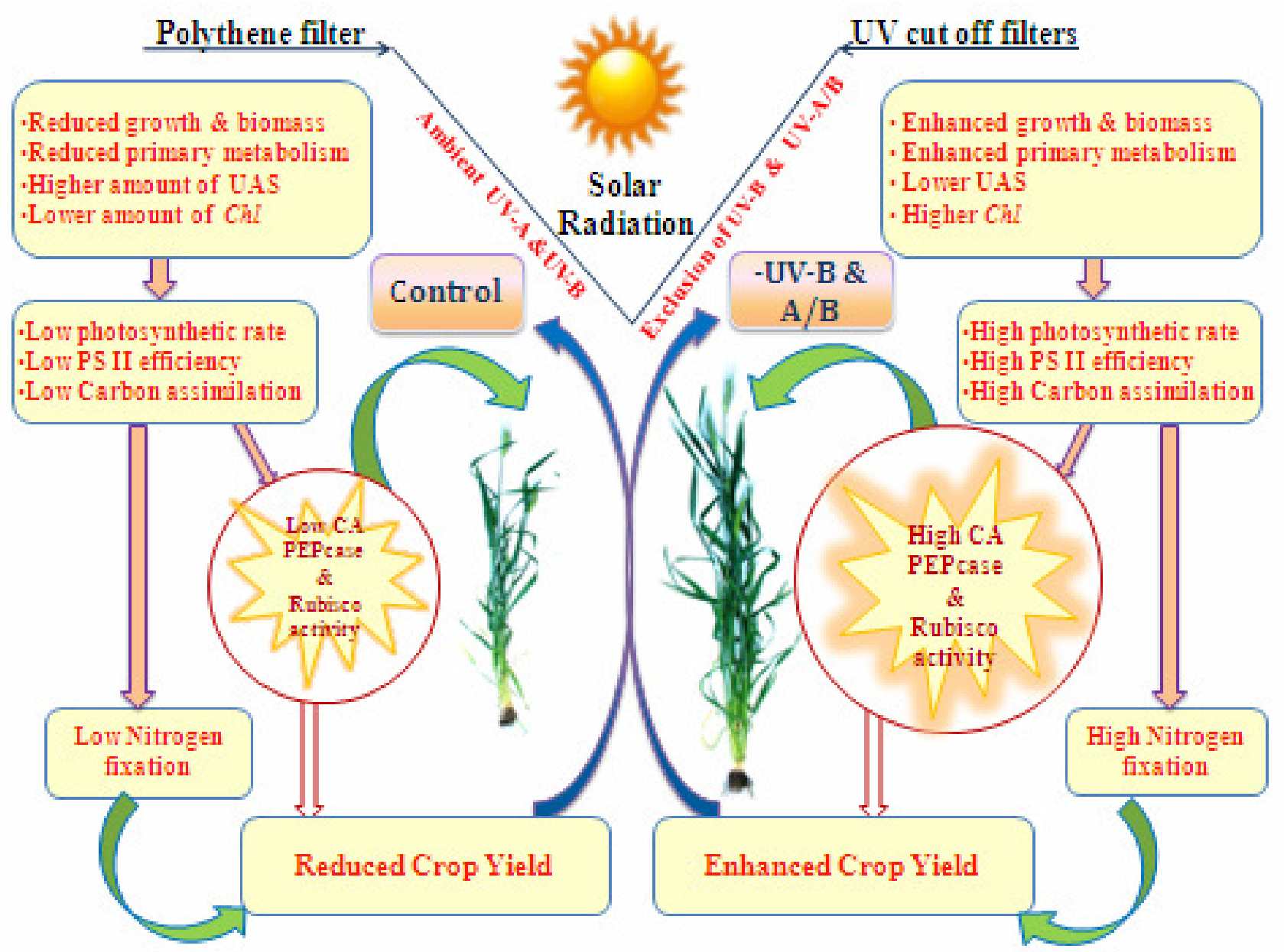

Fig. 1. A model to summarize the growth, photosynthetic and yield responses to ambient UV radiation by exclusion of solar UV

using UV exclusion filters there is a possibility of developing chemicals that can selecting absorb UV light part of the solar spectrum without interfering in the transmission of PAR part of the solar spectrum. Exclusion of UV radiations increases overall processing of light energy per leaf sample and as a consequence higher amounts of ATP and NADPH are produced and thus, increase the capacity for ribulose-1,5-bisphosphate/ phosphoenol pyruvate regeneration. Thus suggesting that the exclusion of UV components from the solar spectrum triggered carbon sequestration in biomass, which seems directly linked to enhancement in photosystem components in field grown plants. Solar UV exclusion could be advantageous from agricultural point to enhance growth and yield of crops. The results indicated a suppressive action of ambient UV-B on growth and photosynthesis; dicots were more sensitive than monocots in this suppression while no great difference in sensitivity was found between $\mathrm{C}_{3}$ and $\mathrm{C}_{4}$ plants.

\section{Acknowledgement}

Financial support by Department of Science Technology, Women Scientists-A Scheme (SR/WOS-A/LS-674/2012-G) to Dr. S. Kataria is thankfully acknowledged.

\section{References}

Albert, K, R., Mikkelsen, T.N., \& Ro-Poulsen, H. (2005). Effects of ambient versus reduced UV-B radiation on high arctic Salix arctica assessed by measurements and calculations of chlorophyll-a fluorescence parameters from fluorescence transients. Physiologia Plantarum, 124, 208-226. doi:10.1111/j.1399-3054.2005.00502.x

Albert, K.R., Mikkelsen, T.N., \& Ro-Poulsen, H. (2008). Ambient UV-B radiation decreases photosynthesis in high arctic Vaccinium uliginosum. Physiologia Plantarum, 133, 199-210. doi:10.1111/j.1399-3054.2008.01065.x

Albert, K.R., Mikkelsen, T.N., Ro-Poulsen, H., Arndal, M.F., \& Michelsen, A. (2011). Ambient UV-B radiation reduces PSII performance and net photosynthesis in high Arctic Salix 
arctica. Environmental Experimental Botany, 72, 439-447. doi:10.1016/j.envexpbot.2010.07.001

Albert, K.R., Mikkelsen, T.N., Ro-Poulsen, H., Michelsen, A., Arndal, M.F., Bredahl, L., Hakansson, K.B., Boesgaard, K., \& Schmidt, N.M. (2010). Improved UV-B screening capacity does not prevent negative effects of ambient UV irradiance on PSII performance in High Arctic plants. Results from a six year UV exclusion study. Journal of Plant Physiology, 167, 1542-1549. doi:10.1016/j.jplph.2010.05.023

Allen D.J., Mckee I.F., Farage P.K. \& Baker N.R. (1997). Analysis of limitations to $\mathrm{CO}_{2}$ assimilation on exposure of leaves of two Brassica napus cultivars to UV-B. Plant, Cell and Environment, 20, 633-640. doi:10.1111/j.1365-3040.1997.00093.x

Allen, D.J., Nougúes, S., \& Baker, N.R. (1998). Ozone depletion and increased UV-B radiation: is there a real threat to photosynthesis? Experimental Botany, 49, 1775- 1778.

Ambasht, N.K., \& Agrawal, M. (1998). Physiological and biochemical responses of Sorghum vulgare plants to supplemental ultraviolet UV-B radiation. Canadian Journal of Botany, 76, 1-5. doi:10.1139/b98-137

Amudha, P., Jayakumar, M., \& Kulandaivelu, G. (2005). Impacts of ambient solar UV (280-400 $\mathrm{nm}$ ) radiation on three tropical legumes. Journal of Plant Biology, 48, 284-291. doi:10.1007/BF03030524

Balouchi, H.R., Sanavy, S.A.M., Emam, Y., Dolatabadian, A. (2009). UV radiation, elevated $\mathrm{CO}_{2}$ and water stress effect on growth and photosynthetic characteristics in durum wheat. Plant Soil Environment, 55, 443-453.

Baroniya, S.S., Kataria, S., Pandey, G.P., \& Guruprasad,K.N. (2011.) Intraspecific variation in sensitivity to ambient Ultraviolet-B radiation in growth and yield characteristics of eight soybean cultivars grown under field conditions. Brazilian J. Plant Physiology. 23(3), 197-202.

Bassman, J.H. (2004). Ecosystem consequences of enhanced solar ultraviolet radiation: secondary plant metabolites as mediators of multiple trophic interactions in terrestrial plant communities. Photochemistry and Photobiology, 79, 382-398. doi:10.1562/SI-03-24.1

Bischof, K., Hanelt, D., \& Wiencke, C. (2000). Effect of ultraviolet radiation on photosynthesis and related enzyme reactions of marine macroalgae. Planta, 211, 555-562. doi: $10.1007 / \mathrm{s} 004250000313$

Bischof, K., Krabs, G., Wiencke, C., \& Hanelt, D. (2002). Solar ultraviolet radiation affects the activity of ribulose-1,5-bisphosphate carboxylase-oxygenase and the composition of photosynthetic and xanthophyll cycle pigments in the intertidal green alga Ulva lactuca L. Planta, 215, 502-509. doi:10.1007/s00425-002-0774-9

Bredahl, L., Ro-Poulsen, H., \& Mikkelsen, T.N. (2004). Reduction of the ambient UV-B Radiation in the High Arctic increases $\mathrm{Fv} / \mathrm{Fm}$ in Salix arctica and Vaccinium uliginosum and reduces stomatal conductance and internal $\mathrm{CO}_{2}$ concentration in Salix arctica. Arcti., Antarctic Alpine Research, 36, 363-368.

Callis, J. (1995). Regulation of protein degradation. Plant Cell, 7, 845-857. doi:10.1105/tpc.7.7.845
Cerovic, Z.G., Ounis, A., Cartelat, A., Latouche, G., Goulas, Y., Meyer, S., \& Moya. I. (2002). The use of chlorophyll fluorescence excitation spectra for the non-destructive in situ assessment of UV-absorbing compounds in leaves. Plant Cell Environment, 25, 1663-1676. doi:10.1046/j.1365-3040.2002.00942.x

Chow, W.S., Strid, A., \& Anderson, J. M. (1992). Recovery of photosynthetic functions and components after supplementary UV-B irradiation. Photosynthetic Research, $34,224$.

Coleman, R.S., \& Day, T.A. (2004). Response of cotton and sorghum to several levels of subambient solar UV-B radiation: a test of the saturation hypothesis. Physiologia Plantarum, 122, 362-372. doi:10.1111/j.1399-3054.2004.00411.x

Dai, Q., Yan, B., Huang, S., Liu, X., Peng, S., Miranda, ... OlsZyk, D.M. (1997). Response of oxidative stress defense systems in rice (Oryza sativa L.) leaves with supplemental UV-B radiation. Physiologia Plantarum, 101, 301-308. doi:10.1111/j.1399-3054.1997.tb01000.x

Day, T.A., \& Vogelmann, T.C. (1995). Alterations in photosynthesis and pigment distribution in pea leaves following UV-B exposure. Physiologia Plantarum, 94, 433-440. doi:10.1111/j.1399-3054.1995.tb00950.x

Demmig-Adams, B., Adams III, W.W. (1992). Photoprotection and other responses of plants to high light stress. Ann. Rev. Plant Physiol. Plant Mol. Boil., 43, 599-626. doi:10.1146/annurev.pp.43.060192.003123

Desimone, M., Henke, A., \& Wagner, E. (1996). Oxidative stress induces partial degradation of the large subunit of ribrose-1,5-bisphosphate carbxylase/ oxygenase in isolated chloroplasts of barley. Plant Physiology, 111, 789-796.

Desimone, M., Wagner, E., \& Johanningmeier, U. (1998). Degradation of active-oxygen-modified ribulose-1,5-bisphosphate carboxylase/oxygenase by chloroplastic proteases requires ATP hydrolysis. Planta, 205, 459-466. doi:10.1007/s004250050344

Flint, S.D., \& Caldwell, M.M. (1996). Scaling plant ultraviolet spectral responses from laboratory action spectra to field spectral weighing factors. J Plant Physiology, 148, 107-114. doi:10.1016/S0176-1617(96)80301-4

Furbank, R.T, \& Taylor, W.C. (1995). Regulation of photosynthesis in C3 and C4 plants: A Molecular Approach. Plant Cell 7: 797-807. doi:10.1105/tpc.7.7.797

Germ, M., Kreft, I., \& Osvald, J. (2005). Influence of UV-B exclusion and selenium treatment on photochemical efficiency of photosystem II, yield and respiratory potential in pumpkins (Cucurbita pepo L.). Plant Physiology Biochemistry, 43, 445-448. doi:10.1016/j.plaphy.2005.03.004

Goncavles, J.F.C., \& Junior, U.M.S. (2005). Utilization of the chlorophyll a fluoresecence technique as a tool for selecting tolerant species to environments of high irradiance. Brazilian Journal of Plant Physiology, 17, 307-313.

Guruprasad, K.N., Bhattacharje, S., Kataria, S., Yadav, S., Tiwari, A., Baroniya, S., ... Mohanty, P. (2007). Growth enhancement of soybean (Glycine max) upon exclusion of UV-B and UV-A components of solar radiation: characterization of 
photosynthetic parameters in leaves. Photosynthetic Research, 94, 299-306. doi:10.1007/s11120-007-9190-0

Hakala-Yatkin, M., Mäntysaari, M., Mattila, H., \& Tyystjärvi, E. (2010). Contributions of visible and ultraviolet parts of sunlight to photoinhibition. Plant Cell Physiology, 51, 1745-1753. doi:10.1093/pcp/pcq133

Hatch, M.D., \& Burnell, J.N. (1990). Carbonic anhydrase activity in leaves and its role in the first step of $\mathrm{C} 4$ photosynthesis. Plant Physiology, 93, 825-828. doi:10.1104/pp.93.2.825

He, J., Huang, L. K., Chow, W. S., Whitecross, M. L., \& Anderson, J. M. (1993). Effects of supplementary ultraviolet-B radiation on rice and pea plants. Australian Journal of Plant Physiology, 20, 129-142. doi:10.1071/PP9930129

He, J., Huang, L.K., Whitcross, M.I. (1994). Chloroplast ultra structure changes in Pisum sativum associated with supplementary UV-B radiation. Plant Cell Environment, 17, 771-775. doi:10.1111/j.1365-3040.1994.tb00170.x

Helsper, J. P. F. G., de Vos, C. H. R., Maas, F. M., Jonker, H. H., van den Broeck, H. C., Jordi, ... Schapendonk, A. H. C. M. (2003). Response of selected antioxidants and pigments in tissues of Rosa hybrida and Fuchsia hybrida to supplemental UV-A exposure. Physiologia Plantarum, 117, 171- 178. doi:10.1034/j.1399-3054.2003.00037.x

Hofmann, R.W., Swinny, E.E., Bloor, S.J., Markham, K.R., Ryan, K.G., Campbell, B.D., ... Fountain, D.W. (2000). Responses of nine Trifolium repen $\mathrm{L}$. populations to ultraviolet-B radiation: differential flavonol glycoside accumulation and biomass production. Annals of Botany, 86, 527-537. doi:10.1006/anbo.2000.1216

Ishida, H., Makino, A., \& Mae, T. (1999) Fragmentation of the large subunit of ribulose-1,5-bisphosphate carboxylase by reactive oxygen species occurs near Gly-329. Journal of Biological Chemistry, 274, 5222-5226. doi:10.1074/jbc.274.8.5222

Ishida, H., Shimizu, S., Makino, A., \& Mae, T. (1998). Light-dependent fragmentation of the large subunit of ribulose-1,5-bisphosphate carboxylase/oxygenase in chloroplasts isolated from wheat leaves. Planta, 204, 305-309. doi:10.1007/s004250050260

Jenkins, G.I. (2008). Environmental regulation of flavonoid biosynthesis. In: Givens, I., Baxter, S., Minihane, A.M., \& Shaw, E. Health Benefits of Organic Food: Effects of the Environment. CABI, pp. 240-260. 0xford.

Jenkins, G.I. (2009). Signal transduction in responses to UV-B radiation. Annual Review of Plant Biology, 60, 407-431. doi:10.1146/annurev.arplant.59.032607.092953

Kataria, S., \& Guruprasad, K.N. (2012a). Solar UV-B and UV-A/B; exclusion effects on intraspecific variations in crop growth and yield of wheat varieties. Field Crops Research, 125, 8-13. doi:10.1016/j.fcr.2011.08.011

Kataria, S., \& Guruprasad, K.N. (2012b). Intraspecific variations in growth, yield and photosynthesis of sorghum varietiesto ambient UV (280-400 $\mathrm{nm}$ ) radiation. Plant Science, 196, 8592. doi:10.1016/j.plantsci.2012.07.011

Kataria, S., \& Guruprasad, K.N. (2014). Exclusion of solar UV components improves growth and performance of
Amaranthus tricolor varieties. Scientia Horticulturae, 174, 36-45. doi:10.1016/j.scienta.2014.05.003

Kataria, S., Guruprasad, K.N., Ahuja, S., \& Singh, B. (2013). Enhancement of growth, photosynthetic performance and yield by exclusion of ambient UV components in $\mathrm{C}_{3}$ and $\mathrm{C}_{4}$ plants. Journal of Photochemistry and Photobiology B: Biology, 127, 140-152. doi:10.1016/j.jphotobiol.2013.08.013

Krause, G.H., Grube, E., Virgo, A., Winter, K. (2003). Sudden exposure to solar UV-B radiation reduces net $\mathrm{CO}_{2}$ uptake and photosystem-I efficiency in shade-acclimated tropical tree seedlings. Plant Physiology, 131, 745-752. doi:10.1104/pp.014076

Mackermess, S.A.H., Surplus, S.L., Jordan, B.R., \& Thomas, B. (1998). Effects of supplementary ultraviolet-B radiation on photosynthetic transcripts at different stages of leaf development and light levels in pea (Pisum sativum L.): role of active oxygen species and antioxidant enzymes. Photochemistry and Photobiology, 68, 88-96. doi:10.1111/j.1751-1097.1998.tb03257.x

Mazza, C.A., Battissta, D., Zima, A.M., Scwarcberg-Bracchitta, M., Giordano, C., Acevedo, A., ... Ballaré, C.L. (1999). The effects of solar ultraviolet- $B$ radiation on the growth and yield of barley are accompanied by increased DNA damage and antioxidant responses. Plant Cell Environment, 22, 61-70. doi:10.1046/j.1365-3040.1999.00381.x

McKenzie, R.L., Aucamp, P.J., Bais, A.F., Björn, L.O., Ilyas, M., \& Madronich, S. (2011). Ozone depletion and climate change: impacts on UV radiation. Photochemistry Photobiology Science 10, 182-198. doi:10.1039/c0pp90034f

Middleton, E.M., \& Teramura, A.H., (1993). The role of flavonol glycosides and carotenoids in protecting soybean from ultraviolet-B damage. Plant Physiology, 103, 741-752.

Mohammed, A.R., \& Tarpley, L. (2010). Effects of high night temperature and spikelet position on yield-related parameters of rice (Oryza sativa L.) plants. Europian Journal of Agronomy, 33, 117-123. doi:10.1016/j.eja.2009.11.006

Morales, L. O., Tegelberg, R., Brosché, M., Keinänen, M., Lindfors, A., \& Pedro-Aphalo, J. (2010). Effects of solar UV-A and UV-B radiation on gene expression and phenolic accumulation in Betula pendula leaves. Tree Physiology, 30, 923-934. doi:10.1093/treephys/tpq051

Moussa, H.R., \& Khodary, S.D.K. (2008). Changes in growth and $14 \mathrm{CO}_{2}$ fixation of Hordeum vulgare and Phaseolus vulgaris induced by UV-B radiation. J. Agric. Soc. Sciences 4, 59-64.

Nogués, S., Allen, D. J., Morison, J. I. L., \& Baker, N. R. (1998). Ultraviolet-B radiation effects on water relations, leaf development and photosynthesis in droughted Pea Plants. Plant Physiology, 117, 173-181. doi:10.1104/pp.117.1.173

O'Leary, M. H., (1982). Phosphoenolpyruvate Carboxylase: An Enzymologist's View. Annual Review of Plant Physiology, 33, 297-315. doi:10.1146/annurev.pp.33.060182.001501

Pal, M., Sharma, A., Abrol, Y.P., \& Sengupta, U.K. (1997). Exclusion of solar UV-B radiation from normal spectrum on growth of mung bean and maize. Agriculture Ecosystem Environment, 61, 29-34. doi:10.1016/S0167-8809(96)01087-0 
Pal, M., Zaidi, P.H., Voleti, S.R., \& Raj, A. (2006). Solar UV-B exclusion effect on growth and photosynthetic characteristics of wheat and pea. Journal of New Seeds, 8, 19-34. doi:10.1300/J153v08n01_02

Rajendiran, K., \& Ramanujam, M.P. (2006). Interactive effects of UV-B irradiation and triadimefon on nodulation and nitrogen metabolism in Vigna radiata plants. Biologia Plantarum 50,709-712. doi:10.1007/s10535-006-0112-3

Rao, M.V., Palijyath, G., \& Ormrod, D.P. (1996). Ultraviolet-B and ozone induced Biochemical changes in antioxidant enzymes of Arabidopsis thaliana. Plant Physiology, 110, 125-136. doi:10.1104/pp.110.1.125

Reddy, K.R., Kakani, V.G., Zhao, D., Koti, S., \& Gao, W. (2004). Interactive effects of ultraviolet-B radiation and temperature on cotton physiology, growth development and hyperspectral reflectance. Journal of Photochemistry Photobiology, 79, 416-427. doi:10.1562/2003-11-19-RA.1

Reddy, R.K., Singh, S.K., Koti, S., Kakani, V.G., Zhao, D., Gao, W., \& Reddy, V.R. (2013). Quantifying the effects of corn growth and physiological responses to Ultraviolet-B radiation for modeling. Agronomy Journal 105, 1367-1377. doi:10.2134/agronj2013.0113

Rinnan, R., Keinanen, M.M, Kasurinen, A., Asikainen, J., Kekki, T.K., Holopainen, T., ... \& Michelsen, A. (2005). Ambient ultraviolet radiation in the Arctic reduces root biomass and alters microbial community composition but has no effects on microbial biomass. Global Change Biology, 11, 564-574. doi:10.1111/j.1365-2486.2005.00933.x

Rousseaux, C.M., Flint, S.D., Searles, P.S., \& Caldwell, M.M. (2004). Plant responses to current solar ultraviolet-B radiation and supplemented solar ultraviolet-B radiation simulating ozone depletion: an experimental comparison. Photochemistry Photobiology, 80, 224-230. doi:10.1562/2004-03-30-RA-129.1

Saile-Mark, M. (1993). Zur beteiligung yon phytohormone an wachstum und blutenbildung verschiedener bohnenkulturvarietaten (Vigna vulgaris I_$_{-}$) in abhangigkeit von artifizeller und solarer UV-B strahlung. Karlsruher Beitr ge zur Entwicklungs-und Okophysiologie der Pflanzen, 13, 1-152.

Saile-Mark, M., Tevini, M. (1997). Effects of solar UV-B radiation on growth, flowering and yield of central and southern European bush bean cultivars (Phaseolus vulgaris L.). Plant Ecology, 128, 115-125. doi:10.1023/A:1009750612676

Schumaker, M.A., Bassman, J.H., Robberecht, R., \& Radamaker, G.K. (1997). Growth, leaf anatomy and physiology of Populus clones in response to solar ultraviolet-B radiation. Tree Physiology, 17, 617-626. doi:10.1093/treephys/17.10.617

Sharma, S., \& Guruprasad, K.N. (2013). Enhancement of root growth and nitrogen fixation in Trigonella by UV-exclusion from solar radiation. Plant Physiology and Biochemistry, 61, 97-102. doi:10.1016/j.plaphy.2012.10.003

Shine, M.B. \& Guruprasad, K.N. (2012). Oxyradicals and PSII activity in maize leaves in the absence of UV components of solar spectrum. Journal of Bioscence, 37, 703-712. doi:10.1007/s12038-012-9248-9
Shiozaki, N, Hattori, I, Gojo, R, \& Tezuka, T. (1999). Activation of growth and nodulation in a symbiotic system between pea plants and leguminous bacteria by near-UV radiation. $J$ Photochemistry Photobiology B: Biol., 50, 33-37. doi:10.1016/S1011-1344(99)00065-2

Strid, A., Chow W. S., \& Anderson, J. M. (1994). UV-B damage and protection at the molecular level in plants. Photosynthesis Research, 39, 475-489. doi:10.1007/BF00014600

Teramura, A.H., 1983. Effects of ultraviolet-B radiation on the growth and yield of crop plants. Physiology Plantarum, 58, 415-427. doi:10.1111/j.1399-3054.1983.tb04203.x

Turcsanyi, E., \& Vass, I. (2000). Inhibition of photosynthetic electron transport by UV-A radiation targets the photosystem II complex. Photochemistry Photobiology, 72, 513-520.

doi:10.1562/0031-8655(2000)072<0513:IOPETB>2.0.CO;2

Turunen, M., Heller, W., Stich, S., Sandermann, H., Sutinen, M.L., \& Norokorpi, Y. (1999). The effects of UV exclusion on the soluble phenolics of young Scots pine seedlings in the subarctic. Environment Pollution, 106, 219-228. doi:10.1016/S0269-7491(99)00070-6

Xiong, F.S., \& Day, T.A. (2001). Effect of solar ultraviolet-B radiation during springtime ozone depletion on photosynthesis and biomass production of Antarctic vascular plants. Plant Physiology, 125, 738-751. doi:10.1104/pp.125.2.738

Xu, C., Natarajan, S., \& Sullivan, J.H., (2008). Impact of solar ultraviolet-B radiation on the antioxidant defense system in soybean lines differing in flavonoids content. Environmental and Experimental Botany, 63, 39-48. doi:10.1016/j.envexpbot.2007.10.029

Yao, Y., Yang, Y., Ren, J., \& Li, C. (2006). UV-spectra dependence of seedling injury and photosynthetic pigment change in Cucumis sativus and Glycine max. Environmental and Experimental Botany, 57, 160-167. doi:10.1016/j.envexpbot.2005.05.009. 